\title{
EDUCAÇÃO AMBIENTAL FORMAL EM UNIDADES DE CONSERVAÇÃO DA REGIÃO HIDROGRÁFICA DO GUAÍBA, RS
}

\author{
Cristina Alves Nascimento ${ }^{1}$ \\ Celson Roberto Canto Silva ${ }^{2}$ \\ Luiz Felipe Velho ${ }^{3}$ \\ Sabrina Letícia Couto da Silva ${ }^{4}$ \\ Rosangela Leal Bjerk ${ }^{5}$ \\ Vili Carlos Saldanha ${ }^{6}$
}

\section{RESUMO}

As Unidades de Conservação (UCs) são áreas especialmente protegidas com o objetivo de conservar a biodiversidade e outros atributos naturais nelas contidos. $\mathrm{O}$ fortalecimento da comunicação, educação e sensibilização pública para participação e controle social das UCs são estratégias apontadas para o alcance desse objetivo, sendo a Educação Ambiental (EA) um instrumento adequado para esse fim. A Estratégia Nacional de Comunicação e Educação Ambiental no âmbito do Sistema Nacional de Unidades de Conservação (ENCEA) trouxe aos diferentes atores das UCs, e de seu entorno, um marco referencial orientador na implantação de programas, projetos e ações de comunicação e EA. No intuito de contribuir para a implementação desta política no Sistema Estadual de Unidades de Conservação (SEUC) do Rio Grande do Sul, o presente trabalho objetivou revelar o perfil, as fragilidades e potencialidades das ações de EA desenvolvidas pelas escolas nas UCs situadas na Bacia Hidrográfica do Guaíba, região com maior impacto antrópico no estado. A metodologia consistiu na aplicação de um questionário semiestruturado às instituições de ensino básico localizadas nos municípios pertencentes a seis bacias hidrográficas dessa Região. Os questionários, compostos por 27 perguntas distribuídas entre abertas e fechadas, foram enviados via correio eletrônico, com o uso da ferramenta

\footnotetext{
${ }^{1}$ Mestranda em Sustentabilidade na Gestão Ambiental pela Universidade Federal de São Carlos - Campus Sorocaba. Bolsista de Desenvolvimento Tecnológico e Industrial da Incubadora Tecno-Social do Instituto Federal de Educação, Ciência e Tecnologia do Rio Grande do Sul (IFRS) - Campus Porto Alegre. E-mail: cristina.anascimento@ hotmail.com.

${ }^{2}$ Doutor em Biologia Animal pela Universidade Federal do Rio Grande do Sul (UFRGS). Docente do IFRS Campus Porto Alegre. E-mail: celson.silva@poa.ifrs.edu.br.

3 Doutor em Sensoriamento Remoto pela UFRGS, Docente do IFRS - Campus Porto Alegre. E-mail: luiz.velho@poa.ifrs.edu.br.

${ }^{4}$ Doutoranda em Engenharia de Produção pela UFRGS. Docente do IFRS - Campus Porto Alegre. E-mail: sabrina.silva@poa.ifrs.edu.br.

${ }^{5}$ Graduada em Biologia pela UFRGS. Técnica Administrativa em Educação do IFRS - Campus Porto Alegre. Email: rosangela.bjerk@poa.ifrs.edu.br.
}

${ }^{6}$ Mestre em Ecologia pela UFRGS. Docente da Rede Pública Municipal de Ensino de Porto Alegre. E-mail: vsaldanha@hotmail.com. 
Google.Docs, no período de março a maio de 2014. Foram respondidos 84 questionários, oriundos de instituições de ensino de 47 municípios pertencentes às seis bacias hidrográficas contempladas no estudo. Com base nos resultados pode-se inferir que é limitada a inserção do tema UC nas escolas da região, evidenciada pela pouca utilização dessas áreas nas atividades de EA. Tal cenário revela que as principais políticas públicas relacionadas à EA não têm alcançado este segmento como um todo. Assim, à luz da ENCEA, percebe-se que há um longo caminho a ser trilhado para a completa implementação dessa política no SEUC/RS. Para tal, são apresentadas neste trabalho algumas medidas que devem ser tencionadas junto aos órgãos gestores das políticas de comunicação e EA no âmbito das UCs e aos órgãos responsáveis pela elaboração do Plano Estadual de EA.

Palavras Chave: Unidade de Conservação; Educação Ambiental; Ensino Formal.

\begin{abstract}
Protected Areas (PAs) are areas specially protected in order to conserve biodiversity and other natural attributes they contain. The strengthening of communication, education and public awareness of social participation and control of protected areas are strategies aimed at achieving this goal, Environmental Education (EE) being an appropriate tool for this purpose. The National Strategy for Environmental Communication and Education under the National Conservation Areas System (ENCEA) brought the different actors of protected areas and their surroundings a landmark framework guiding the implementation of programs, projects and actions of communication and EA. In order to contribute to the implementation of this policy in the State System of Conservation Units (SEUC) of Rio Grande do Sul, this study aimed to reveal the profile, weaknesses and potential of environmental education initiatives developed by schools located in protected areas located in the Guaiba river basin district, region with the highest human impact in the state. The methodology consisted of applying a semi-structured questionnaire to basic educational institutions located in the municipalities belonging to six watersheds in this region. The questionnaires consisting of 27 questions distributed between open and closed, were sent via e-mail, using the Google.Docs tool, from March to May 2014. 84 questionnaires were answered, coming from educational institutions of 47 municipalities belonging to the six watersheds included in the study. Based on the results it can be inferred that it is limited to insertion of the UCs subject in schools in the region, as evidenced by the low use of these areas of activities EA.This scenario shows that the main public policies related to EA have not reached this segment as a whole. In the light of ENCEA, one realizes that there is a long way to go to fully implement this policy in SEUC / RS. For this purpose, it is presented in this paper some measures to be tensioned with the managers of communication policies organs and EA within the UCs and bodies responsible for drafting the State Plan of EA.
\end{abstract}

Keywords: Protected Areas; Environmental Education; Formal Education.

\title{
INTRODUÇÃO
}

Há tempos as alterações ambientais impulsionam movimentos que defendem a conservação da biodiversidade como um instrumento para a melhoria da qualidade de vida, 
contribuindo para o surgimento e desenvolvimento da Educação Ambiental - EA (SILVA \& PESSOA, 2010).

No Brasil, a Política Nacional de Meio Ambiente, que tem por objetivo a preservação, a melhoria e a recuperação da qualidade ambiental, traz como um de seus princípios a "educação ambiental a todos os níveis de ensino, inclusive a educação da comunidade, objetivando capacitála para participação ativa na defesa do meio ambiente" (BRASIL, 1981).

A Lei no 9.795/1999 instituiu a Política Nacional de Educação Ambiental (PNEA) (BRASIL, 1999), a qual incumbe os órgãos integrantes do Sistema Nacional de Meio Ambiente (SISNAMA) a promoverem ações de EA integradas aos programas de conservação, recuperação e melhoria do meio ambiente. Essas atividades devem ser um componente essencial e permanente da educação nacional, estando presente em todos os níveis e modalidades do processo educativo, em caráter formal e não formal. Continuamente, esta lei conceitua a EA formal como aquela "desenvolvida no âmbito dos currículos das instituições de ensino públicas e privadas" e a EA não formal como "as ações e práticas educativas voltadas à sensibilização da coletividade sobre as questões ambientais e à sua organização e participação na defesa da qualidade do meio ambiente".

Em 2005, como produto de uma série de iniciativas do governo em relação à EA, foi proposto o Programa Nacional de Educação Ambiental (ProNEA), que atualmente se encontra em sua $3^{a}$ edição. Dentre outras linhas de ação e estratégias, o Programa estimula a inserção da EA no planejamento e na execução de ações relacionadas à preservação da biodiversidade em Unidades de Conservação (UCs) e seu entorno (MMA, 2005).

Em 2006, para orientar as ações desenvolvidas nas áreas protegidas, buscando o estabelecimento de um sistema abrangente ecologicamente representativo, efetivamente manejado e integrado a áreas terrestres e marinhas mais amplas, até 2015, foi instituído o Plano Estratégico Nacional de Áreas Protegidas (PNAP). O Plano tem como um de seus objetivos "fortalecer a comunicação, a educação e a sensibilização pública para a participação e controle social sobre o Sistema Nacional de Unidades de Conservação", apontando diversas estratégias para alcança-lo, dentre elas: "promover programas de EA que viabilizem o acesso às informações e o entendimento da importância e dos benefícios das UCs" e "propor a incorporação do tema UC e outras áreas protegidas aos currículos escolares formais” (BRASIL, 2006).

Recentemente, a formulação da Estratégia Nacional de Comunicação e Educação Ambiental no âmbito do Sistema Nacional de Unidades de Conservação (ENCEA), em consonância com as demais políticas citadas, trouxe aos diferentes atores das UCs e de seu entorno um marco referencial orientador na implantação de programas, projetos e ações de comunicação e EA. Voltado ao (re)conhecimento, valorização, criação e implementação das UCs, o documento apresenta diversas diretrizes e ações estratégicas a serem implementadas, dentre as quais a inserção das UCs como temática no ensino formal e não-formal (MMA, 2011). 
No âmbito do estado do Rio Grande do Sul, a Lei no 13.597/2010 instituiu a Política Estadual de Educação Ambiental e criou o Programa Estadual de Educação Ambiental (RIO GRANDE DO SUL, 2010). Nestes documentos são reafirmados os princípios e diretrizes do ProNEA e o papel da EA não formal para a sensibilização da sociedade quanto à importância das UCs, nos termos do Sistema Nacional de Unidades de Conservação (SNUC) e do Sistema Estadual de Unidades de Conservação (SEUC/RS), assim como a sensibilização ambiental das comunidades tradicionais ligadas às UCs. No que tange ao papel da EA formal, pontua, de forma inédita, que todas as escolas deverão incorporar em seus currículos, entre outros aspectos relacionados à conservação ambiental, o tema espaços territoriais especialmente protegidos.

Atualmente, segundo dados da Secretaria Estadual de Meio Ambiente (SEMA, 2014a), o SEUC/RS é constituído pelo conjunto de 22 UCs estaduais, 22 UCs municipais e uma RPPN, que compreendem apenas $1,19 \%$ do território do estado. Sendo que, de acordo com o Decreto $\mathrm{n}^{\circ}$ 34.256/1992, as atividades de EA devem ser incentivadas em todas as categorias de UCs gaúchas (RIO GRANDE DO SUL, 1992).

Estudos recentes, abordando a EA em UCs localizadas no Rio Grande do Sul (MUHLE, 2012; PISSATTO et al., 2012), revelaram que as ações de EA são ferramentas valiosas para a superação do distanciamento entre o homem e a natureza, proporcionando aos envolvidos uma maior compreensão quanto à função e à importância desses espaços. No entanto, como pontua Pissatto et al. (2012), tais ações ainda são secundarizadas dentro dos programas de manejo, principalmente devido a carências de recursos financeiros e humanos. Portanto, a adoção dessa política na esfera do SEUC/RS requer a avaliação inicial das potencialidades e das fragilidades das ações que vêm sendo conduzidas, de modo a gerar um referencial para posterior monitoramento e avaliação de resultados.

No Rio Grande do Sul, a Política Estadual de Gestão de Recursos Hídricos, instituída pela Lei $n^{\text {o }}$ 10.350/1994 (RIO GRANDE DO SUL, 1994), estabeleceu três grandes regiões hidrográficas em sua área territorial: a Região Hidrográfica do Guaíba, a Região Hidrográfica do Uruguai e a Região Hidrográfica das Bacias Litorâneas. Por sua vez, estas regiões são subdivididas em 25 bacias hidrográficas, conforme mostra a Figura 1. 


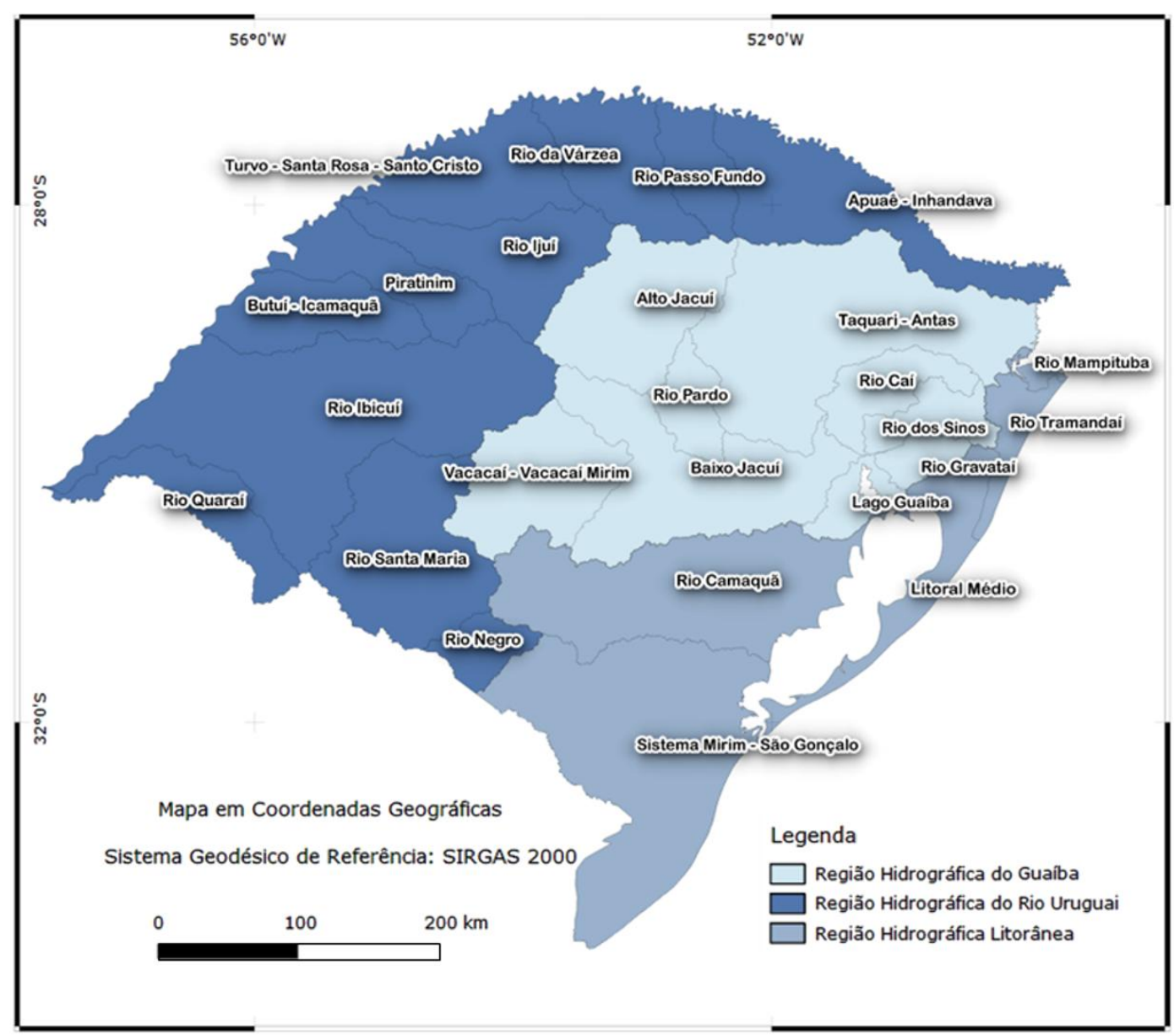

Figura 1 - Regiões e Bacias Hidrográficas do Rio Grande do Sul. Fonte: Nascimento et al., 2015.

A Região Hidrográfica do Guaíba situa-se na porção centro-oeste do estado, abrangendo as províncias geomorfológicas do Planalto Meridional, da Depressão Central e, em menor área, da Planície Costeira Interior e do Escudo Sul-Rio-Grandense. Estima-se que sua área corresponda a $84.800 \mathrm{~km}^{2}$, abrangendo cerca de $30 \%$ da área do estado, na qual estão inseridos, total ou parcialmente, 256 municípios (SEMA, 2012). O território total possui quase seis milhões de habitantes, ou seja, 61\% da população do Rio Grande do Sul, sendo o eixo mais urbanizado constituído pela região metropolitana de Porto Alegre e por uma faixa de municípios em Caxias do Sul. Trata-se, portanto, de uma região sob forte impacto antrópico, tanto pela intensa atividade agrícola e industrial, quanto pelo processo de concentração urbana (FEPAM, 2014). Parte desses ecossistemas está protegida através de 24 UCs pertencentes ao SEUC/RS, sendo estas: uma Esec, um RVS, uma RPPN, duas ReBios, duas Aries, quatro Parques Naturais Municipais, seis Parques Estaduais e sete APAs (SEMA, 2014).

O presente estudo constitui-se num ponto de partida para o conhecimento das ações de EA em curso nas UCs pertencentes ao SEUC/RS. Especificamente, busca identificar o perfil, as 
fragilidades e as potencialidades das ações desenvolvidas no âmbito do ensino formal. Visando, com isso, contribuir para a adoção da ENCEA.

\section{MATERIAL E MÉTODOS}

O referencial geográfico do estudo, adotado para determinação do público alvo e da metodologia de planejamento e seleção de amostras da investigação, foi a bacia hidrográfica e seu pertencimento a Região Hidrográfica do Guaíba. As bacias hidrográficas abordadas foram definidas selecionando-se aleatoriamente 11 UCs pertencentes ao SEUC/RS, considerando-se os diferentes órgãos gestores (município e estado) e os dois grupos de uso (proteção integral e uso sustentável), conforme a Tabela I. Foram contempladas as seguintes bacias hidrográficas: Baixo Jacuí, Rio Caí, Rio Gravataí, Lago Guaíba, Rio dos Sinos e Taquari-Antas.

Tabela I - Unidades de Conservação selecionadas, com seus respectivos órgãos gestores, tipos de uso e bacias hidrográficas.

\begin{tabular}{|c|c|c|c|}
\hline Unidade de Conservação & $\begin{array}{l}\text { Órgão } \\
\text { Gestor }\end{array}$ & Tipo de Uso & Bacia Hidrográfica \\
\hline Área de Proteção Ambiental Rota do Sol & Estadual & Sustentável & Taquari-Antas e Sinos \\
\hline Parque Estadual Delta do Jacuí & Estadual & Proteção integral & $\begin{array}{l}\text { Baixo Jacuí, Caí, } \\
\text { Sinos e Lago Guaíba }\end{array}$ \\
\hline Parque Estadual do Tainhas & Estadual & Proteção integral & Taquari-Antas \\
\hline RPPN Estadual Barba Negra & Estadual & Sustentável & Lago Guaíba \\
\hline Parque Estadual de Itapuã & Estadual & Proteção integral & Lago Guaíba \\
\hline $\begin{array}{l}\text { Parque Natural Municipal Dr. Tancredo } \\
\text { Neves }\end{array}$ & Municipal & Proteção integral & Gravataí \\
\hline Parque Natural Municipal Morro do Osso & Municipal & Proteção integral & Lago Guaíba \\
\hline Parque Natural Municipal da Ronda & Municipal & Proteção integral & Sinos \\
\hline $\begin{array}{l}\text { Área de Relevante Interesse Ecológico São } \\
\text { Bernardo }\end{array}$ & Municipal & Sustentável & Sinos \\
\hline Área de Proteção Ambiental de Caraá & Municipal & Sustentável & Sinos \\
\hline Área de Proteção Ambiental de Riozinho & Municipal & Sustentável & Sinos \\
\hline
\end{tabular}

A pesquisa consistiu na aplicação de um questionário semiestruturado a instituições de ensino das bacias hidrográfica abrangidas pelo estudo, via correio eletrônico, com o uso da ferramenta Google Docs, no período de março a maio de 2014. O questionário aplicado, elaborado com base em outro similar, proposto por Mamede (2008), foi composto por 27 perguntas, distribuídas entre abertas e fechadas, e dividido em três blocos: identificação da instituição respondente, relacionamento desta com as UCs e caracterização das ações de EA desenvolvidas.

O universo amostral foi constituído por todas as instituições de ensino básico localizadas nos municípios pertencentes às bacias hidrográficas selecionadas. Para a identificação do mesmo, 
procedeu-se a elaboração de um banco de dados dessas instituições, a partir do cadastro da Secretaria da Educação do Estado do Rio Grande do Sul (SEDUC, 2013).

O tamanho amostral foi definido com base numa margem de erro de 5\%, estimativa proporcional de p=0,50 e nível de confiança de 95\% (SILVA et al., 1997), sendo consideradas as redes e níveis/modalidades de ensino separadamente, o que resultou num total de 1.811 questionários enviados. A seleção das escolas foi feita de forma aleatória. Procedeu-se o envio do questionário até o recebimento da resposta por parte da escola ou até o número máximo de dez envios.

\section{RESULTADOS}

Foram respondidos 84 questionários, correspondendo a 4,6\% das instituições de ensino amostradas. Tais escolas são pertencentes a 47 municípios, que abrangem as seis bacias hidrográficas contempladas no estudo.

Os questionários foram respondidos predominantemente por diretores (42,9\%) e professores $(27,4 \%)$. As instituições respondentes estão inseridas principalmente no ambiente urbano $(56,0 \%)$, sendo a quase totalidade pública, da rede municipal $(54,8 \%)$ e estadual $(32,1 \%)$, e majoritariamente de nível fundamental $(41,7 \%)$. A maioria das instituições revelou possuir até 30 professores $(68,3 \%)$, 50 técnicos $(96,4 \%)$ e 500 alunos $(76,2 \%)$.

Apenas $35,7 \%$ das instituições de ensino reconheceram desenvolver atividades de EA em UCs, sendo que 28,6\% em áreas pertencentes ao SEUC/RS e 7,1\% em UCs federais. Dentre as demais, 33,3\% não responderam à pergunta e 31,0\% informaram realizar essas atividades em outras áreas, como Parques Municipais, Jardins Botânicos, áreas particulares e outros ambientes no entorno das escolas.

Das 45 UCs cadastradas no SEUC/RS, 12 foram citadas pelas instituições, representando 26,7\% do total, todas localizadas na Região Hidrográfica do Guaíba. Com relação ao órgão gestor, $50 \%$ são municipais, $41,7 \%$ estaduais e $8,3 \%$ particular. Dentre estas, as mais mencionadas foram a ReBio Lami José Lutzenberger (16,1\%), a APA do Banhado Grande (12,9\%), a APA Estadual Delta do Jacuí (12,9\%), o Parque Estadual de Itapuã (12,9\%) e a APA do Caraá (12,9\%). Quanto as UCs federais mais citadas, destacam-se a Flona de Canela e a Flona de São Francisco de Paula.

Todas as UCs do SEUC/RS mencionadas estão inseridas, pelo menos em parte, em municípios dispostos na Bacia Hidrográfica do Lago Guaíba, pertencendo a região metropolitana de Porto Alegre - com exceção da APA do Caraá. De fato, 94,6\% das UCs informadas estão inseridas nas mesmas bacias hidrográficas das cidades das instituições estudadas, o que significa que as mesmas mantêm contato com UCs localizadas em sua proximidade. 
Quanto ao tipo de atividade de EA desenvolvida nas UCs, todos obtiveram mais de 50\% de suas freqüências nula e eventual. Aqueles mais citados como mensal e trimestral foram os cursos ou palestras de EA (16,7\%), os eventos diversos (feiras, atividades culturais, esportivas, etc.) $(14,3 \%)$ e os passeios ou trilhas ecológicas (11\%), conforme explicita a Figura 2. Destacase a freqüência de ações em prol da gestão da UC (participação em planos de manejo, em reuniões de conselhos gestores, etc.), que nunca foram realizadas em 63,1\% das instituições de ensino.

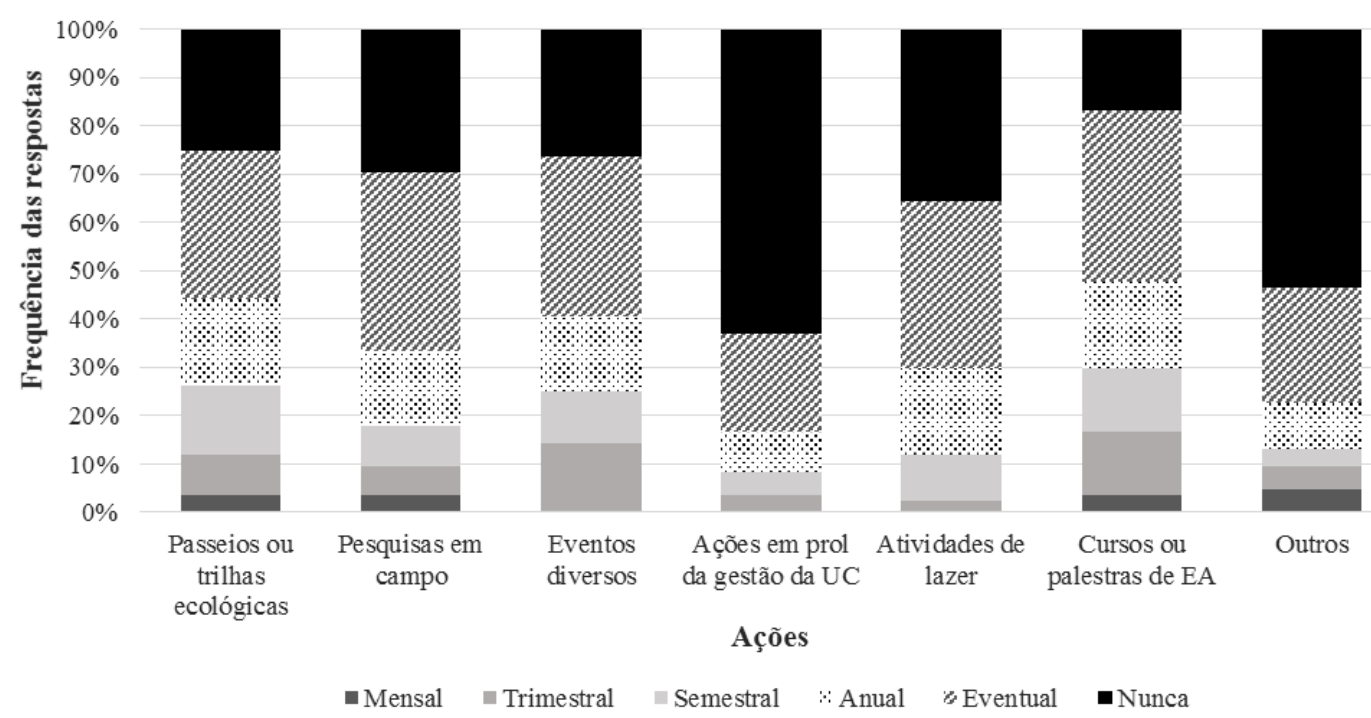

Figura 2 - Frequência, em porcentagem, das ações de EA desenvolvidas pelas instituições de ensino nas Unidades de Conservação. Fonte: Nascimento et al., 2015.

As principais motivações para as instituições executarem essas atividades em UCs (Figura 33) foram iniciativas da comunidade escolar (professores, estudantes, direção, funcionários e pais) (67,9\%), interesse dos profissionais da instituição $(56,0 \%)$ e os Parâmetros Curriculares Nacionais do Ministério da Educação (54,8\%). A adoção da ENCEA foi uma das motivações com menor frequência de citações entre as escolas estudadas $(2,4 \%)$. 


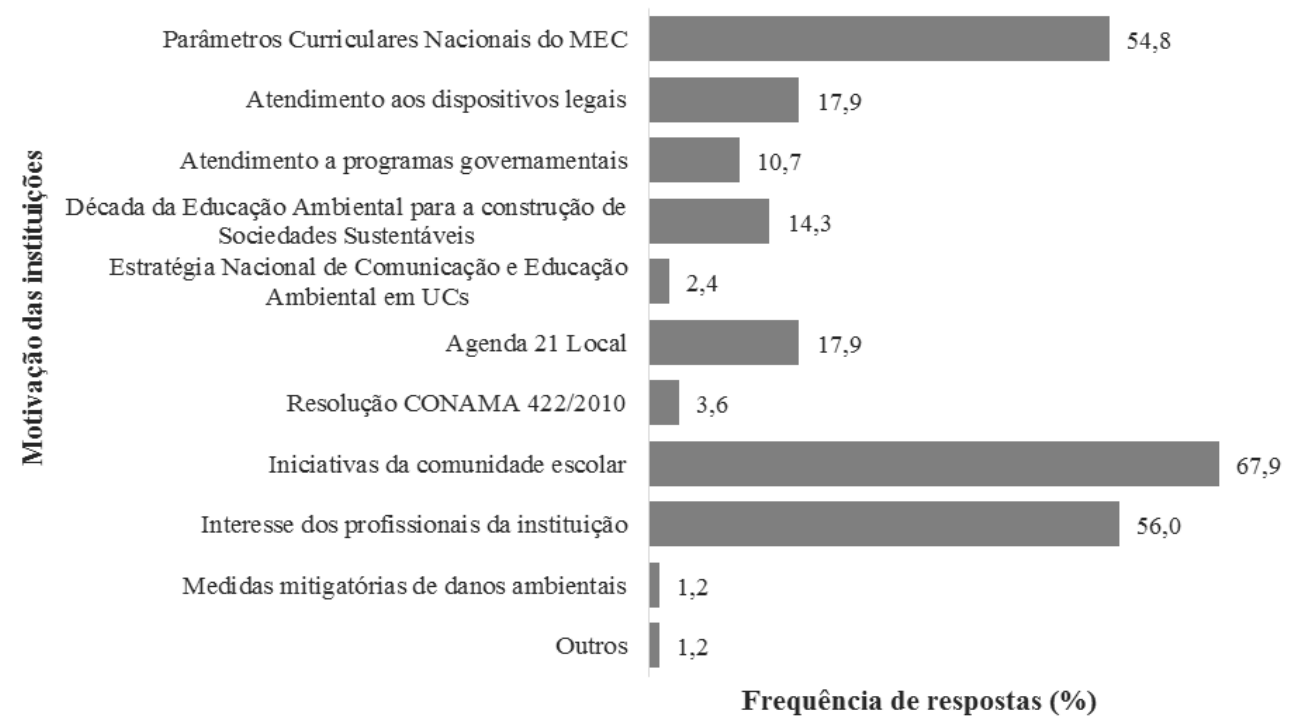

Figura 3 - Frequência, em porcentagem, das motivações das instituições de ensino para desenvolverem ações de EA nas Unidades de Conservação. Fonte: NASCIMENTO et al., 2015.

As escolas estudadas afirmam que as atividades de EA nas UCs foram apoiadas principalmente por material pedagógico de produção própria sobre temas ambientais $(60,7 \%)$ e internet ou outras tecnologias virtuais (CDs, DVDs, sites e blogs de turismo, de ONGs, de EA, etc.) $(57,1 \%)$, como demonstrado na Figura 44. O material informativo elaborado pela UC foi citado por apenas $26,2 \%$ das escolas.

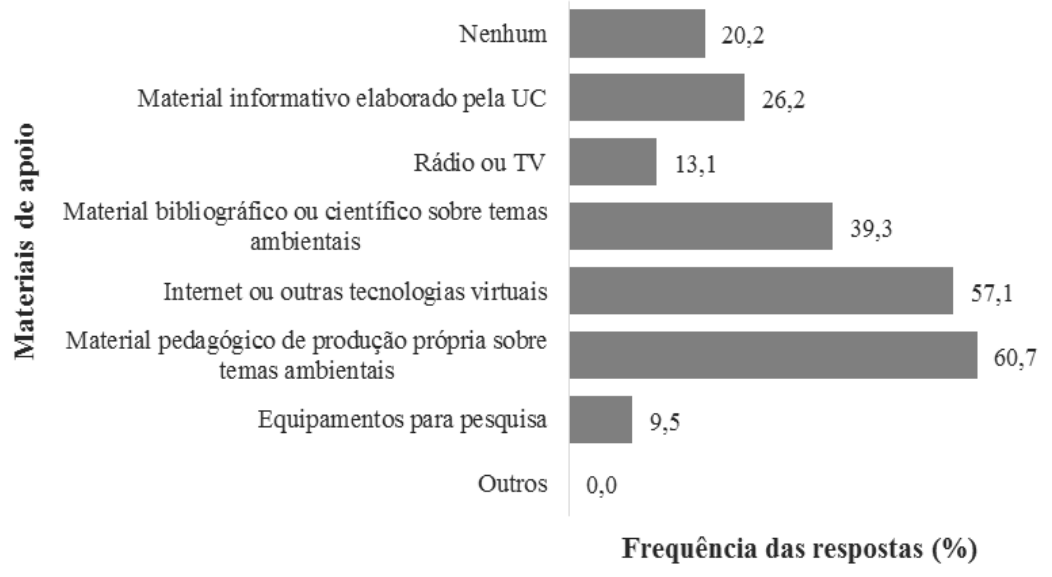

Figura 4 - Frequência, em porcentagem, dos materiais de apoio utilizados pelas instituições de ensino nas atividades de EA realizadas em Unidades de Conservação. Fonte: Nascimento et al., 2015.

Ao serem analisadas as dificuldades encontradas no desenvolvimento das atividades de EA nas UCs (Figura 3), aquelas apontadas como mais negativas pelas escolas foram a 
disponibilidade de recursos financeiros para transporte dos alunos $(61,8 \%)$ e a falta de profissionais qualificados em EA $(42,3 \%)$.

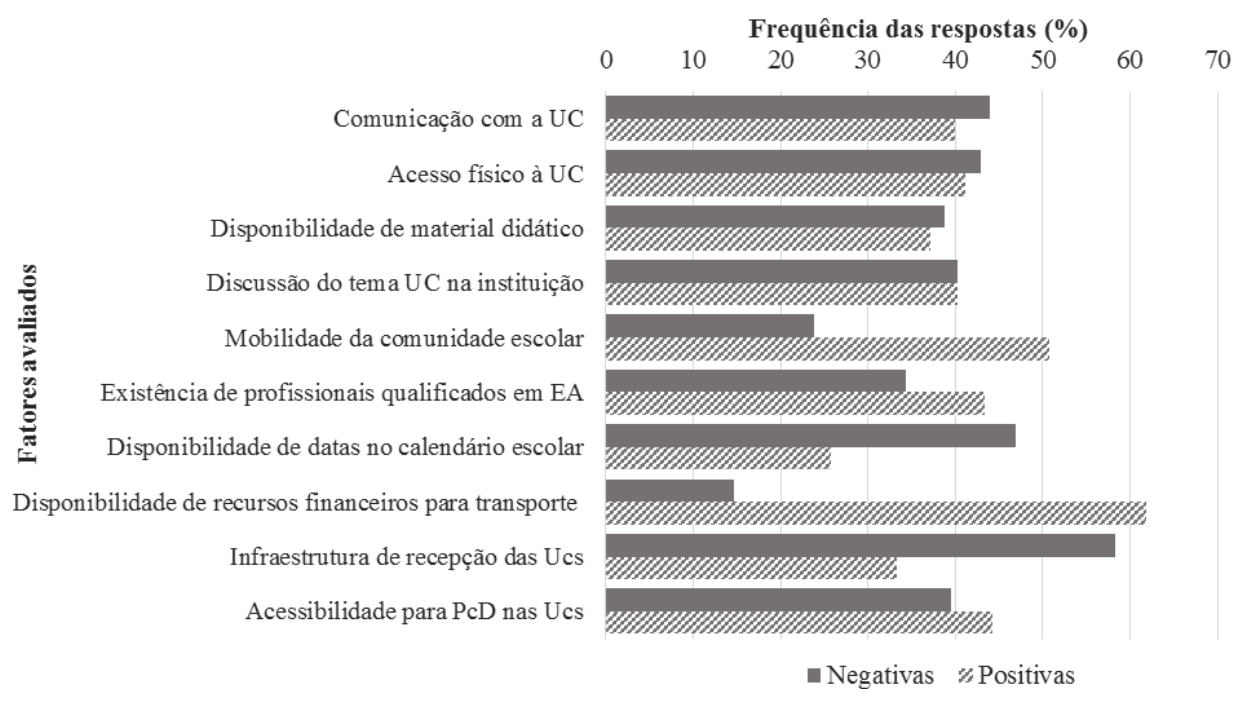

Figura 3 - Frequência, em porcentagem, das dificuldades encontradas pelas instituições de ensino no desenvolvimento das atividades de EA nas UCs. Fonte: Nascimento et al., 2015.

\section{CONCLUSÕES}

Embora o índice de retorno de questionários possa ser considerado baixo, levando-se em conta que se refere a apenas uma Região Hidrográfica do Rio Grande do Sul, o número absoluto de escolas participantes (84) é muito satisfatório. Segundo Marconi \& Lakatos (2005), questionários enviados aos entrevistados alcançam em média apenas $25 \%$ de devolução. No presente estudo, graças ao envio via mensagem eletrônica, com base no endereço informado no cadastro da SEDUC (2013), diversas inconsistências - como endereços eletrônicos desatualizados, caixas de correio eletrônico cheias, falta de frequência na verificação de e-mails, falhas técnicas de transmissão, entre outros - podem ter resultado em um índice de respostas aquém do esperado.

Outro aspecto a ser preliminarmente ressaltado refere-se a quase inexistência de outros diagnósticos que abordem as ações de EA formal em UCs. Exceto o trabalho de Mamede (2008), cuja metodologia contemplou a avaliação das ações, tanto sob o ponto de vista das escolas, quanto dos gestores das UCs, os demais estudos (MUHLE, 2012; PISSATTO et al., 2012, LOKSCHIN, 2014) referem-se geralmente às percepções emitidas pelos gestores das UCs.

Desta forma, o presente trabalho é uma importante contribuição para o conhecimento da EA desenvolvida junto a UCs no Rio Grande do Sul, principalmente por traçar um cenário construído a partir da percepção das instituições de ensino, diferentemente de outros estudos que abordam o tema sob o ponto de vista dos gestores ou executores das políticas públicas de conservação da biodiversidade. Neste sentido, este trabalho permite constatar o quanto essas 
políticas permeiam a trama social e chegam até o segmento das instituições de ensino, assim como possibilita inferir de que maneira as escolas fazem uso dessas políticas, com base nas suas concepções, limitações e possibilidades.

Um possível perfil gerado por este estudo caracterizaria escolas que desenvolvem diversas ações de EA relacionadas à conservação ambiental, contudo, não necessariamente em UCs, utilizando prioritariamente as áreas naturais disponíveis ou de mais fácil acesso na sua região. A pouca utilização das UCs pelas instituições de ensino resulta de um complexo de fatores, no qual estão incluídos desde a limitada inserção da temática UC no ensino formal, o que provavelmente gera o desconhecimento da natureza e do papel dessas áreas, até a carência de recursos e parcerias para a execução das ações, principalmente no que diz respeito ao custeio de transporte.

Essa limitada inserção da temática das áreas protegidas nas escolas parece estar relacionada a pouca capacidade das UCs em desenvolver ações de comunicação e EA junto a esse público e à carência de profissionais qualificados em EA nas escolas. Desta forma, as principais políticas públicas relacionadas à EA não têm alcançado este segmento como um todo.

Assim, à luz da ENCEA, percebe-se que há um longo caminho a ser trilhado para a completa implementação dessa política no SEUC/RS. Dentre as principais medidas que podem contribuir para essa efetivação destaca-se a implementação, junto aos órgãos governamentais responsáveis, da infraestrutura e suporte técnico necessário à formulação e implantação de programas e ações de comunicação e EA nas UCs. Além disso, deve-se buscar inserir a temática da comunicação e EA em cursos, oficinas e programas de formação continuada de servidores públicos que atuem no SEUC/RS.

No âmbito do Órgão Gestor da Política Estadual de Educação Ambiental, quando da elaboração do PlanEA-RS, é importante que se proponham ações que: articulem as secretarias de educação com as instituições de ensino para o desenvolvimento e implantação de metodologias que utilizem as UCs como cenário para o ensino e a pesquisa, bem como espaço para a adoção de práticas sustentáveis; destinem recursos do orçamento público do estado para a implementação de ações de EA que versem sobre a temática das UCs e viabilizem o deslocamento do público escolar às UCs; e promovam a formação de educadores ambientais, de modo descentralizado, através do Ensino a Distância, em cursos que incluam a temática das UCs nos currículos.

\section{AGRADECIMENTOS}

Agradecemos à Fundação de Amparo à Pesquisa do Rio Grande do Sul (FAPERGS) pelo apoio financeiro, à Secretaria Estadual do Meio Ambiente do Rio Grande do Sul (SEMA) pelo apoio institucional e ao Instituto Federal de Educação, Ciência e Tecnologia do Rio Grande do Sul (IFRS) pelo apoio acadêmico. 


\section{REFERÊNCIAS BIBLIOGRÁFICAS}

BRASIL. Lei $\mathbf{n}^{\mathbf{0}}$ 6.938, de 31 de agosto de 1981. Dispõe sobre a Política Nacional do Meio Ambiente, seus fins e mecanismos de formulação e aplicação, e dá outras providências. Diário Oficial da União, Brasília, 1981.

BRASIL. Lei $\mathbf{n}^{0}$ 9.795, de 27 de abril de 1999. Dispõe sobre a educação ambiental, institui a Política Nacional de Educação Ambiental e dá outras providências. Diário Oficial da União, Brasília, 1999.

BRASIL. Decreto $\mathbf{n}^{\mathbf{0}}$ 5.758, de 13 de abril de 2006. Institui o Plano Estratégico Nacional de Áreas Protegidas - PNAP, seus princípios, diretrizes, objetivos e estratégias, e dá outras providências. Diário Oficial da União, Brasília, 2006.

FEPAM. Qualidade Ambiental: Região Hidrográfica do Guaíba. Fundação Estadual de Proteção Ambiental Henrique Luiz Roessler, Porto Alegre, 2014. Disponível em: < http://www.sema.rs.gov.br/conteudo.asp?cod_menu=54 >. Acesso: 19/04/2014.

LOKSCHIN, L. X. Educação Ambiental em Unidades de Conservação no Rio Grande do Sul. Viçosa: Anais do III Simpósio Nacional de Áreas Protegidas, 2014. P. 133-141.

MAMEDE, S. Diagnóstico e Mapeamento das Ações de Comunicação e Educação Ambiental no Âmbito do SNUC. Ministério do Meio Ambiente, Instituto Chico Mendes de Conservação da Biodiversidade, 2008. 124 p.

MARCONI, M. A.; LAKATOS, E. M. Fundamentos de metodologia científica. 6 ed. São Paulo: Atlas, 2005.

MMA. Programa Nacional de Educação Ambiental - ProNEA. Ministério do Meio Ambiente, Diretoria de Educação Ambiental, Ministério da Educação. Coordenação Geral de Educação Ambiental. 3. ed. Brasília: Ministério do Meio Ambiente, 2005. 105 p.

MMA. Diretrizes para a Estratégia Nacional de Comunicação e Educação Ambiental em Unidades de Conservação - ENCEA. Brasília: Ministério do Meio Ambiente, 2011. 40 p.

MUHLE, R. P. Ações de Educação Ambiental em Unidades de Conservação Estaduais do Rio Grande do Sul. 2012. 46 f. Trabalho de Conclusão de Curso (Especialização em Diversidade e Conservação da Fauna) - Instituto de Biociências, Universidade Federal do Rio Grande do Sul, Porto Alegre, 2012.

PISSATTO, M.; MERCK, A. M. T.; GRACIOLI, C. R. Ações de Educação Ambiental realizadas no âmbito de três Unidades de Conservação do Rio Grande do Sul. Santa Maria, Revista Eletrônica em Gestão, Educação e Tecnologia Ambiental, v. 5, n. 5, 2012. P. 804-812. Disponível em: <http://cascavel.ufsm.br/revistas/ojs2.2.2/index.php/reget/article/view/4242/2810>. Acesso: 17/01/2014.

RIO GRANDE DO SUL. Decreto no 34.356, de 2 de abril de 1992. Cria o Sistema Estadual de Unidades de Conservação e dá outras providências. Diário Oficial do Estado, Porto Alegre, 1992. 
RIO GRANDE DO SUL. Lei no 10.350, de 30 de dezembro de 1994. Institui o Sistema Estadual de Recursos Hídricos, regulamentando o artigo 171 da Constituição do Estado do Rio Grande do Sul. Diário Oficial do Estado, Porto Alegre, 1994.

RIO GRANDE DO SUL. Lei $\mathbf{n}^{\mathbf{0}} \mathbf{1 3 . 5 9 7}$, de 30 de dezembro de 2010. Dá nova redação à Lei n. ${ }^{\circ}$ 11.730, de 9 de janeiro de 2002, que dispõe sobre a Educação Ambiental, institui a Política Estadual de Educação Ambiental, cria o Programa Estadual de Educação Ambiental, e complementa a Lei Federal n. ${ }^{\circ}$ 9.795, de 27 de abril de 1999, no Estado do Rio Grande do Sul, regulamentada pelo Decreto Federal n. ${ }^{\circ} 4.281$, de 25 de junho de 2002. Diário Oficial do Estado, Porto Alegre, 2010.

SEDUC. Pesquisa de escolas do Rio Grande do Sul. Secretaria da Educação do Estado do Rio Grande do Sul, 2013. Disponível em: <http://www.educacao.rs.gov.br/pse/html/busca_escolas.jsp>. Acesso: 15/08/2013.

SEMA. Relatório Anual sobre a Situação dos Recursos Hídricos no Estado do Rio Grande do Sul - Ano 2009/2010. Porto Alegre: Secretaria Estadual do Meio Ambiente, 2012. 169 p.

SEMA. Unidades de Conservação. Secretaria Estadual do Meio Ambiente, Porto Alegre, 2014. Disponível em: <http://www.sema.rs.gov.br/>. Acesso: 15/04/2014.

SILVA, E. M. DA; SILVA, E. M. DA; GONÇALVES, V.; MUROLO, A. C. Estatística para os cursos de Economia, Administração e Ciências Contábeis. São Paulo, Editora Atlas, v. 2, 1997. $135 \mathrm{p}$. 